\title{
ASILIDS FEEDING ON BUMBLEBEES IN NEW ENGLAND
}

\section{By Stanley W. BRomley}

In Dr. O. E. Plath's excellent book on Bumblebees ("Bumblebees and Their Ways", Macmillan Company, New York City, 1934) he records two instances (p. 62) of bumblebees captured by Robber flies. In both cases the large bumblebeelike Bombomima (Dasyllis) grossa (Fabr.) was the captor. As I have collected a number of records of Robber flies preying on bumblebees, it might be of interest to present a summary of these records. Five different species of Asilids were observed to kill bumblebees in New England with a total of 76 bumblebees ${ }^{1}$ recorded as prey. The dates of capture range from 1910 to 1922 and were confined to Southern New England, most of them from Massachusetts.

AsILID Bumblebee PREY RECORdS

Proctacanthus Philadelphicus Macq. $\quad 30$

Diogmites (DEROMYiA) UMBRINUS Loew 29

PROCTACANTHUS RUFUS Williston 10

Promachus FITCHII Osten Sacken 6

BOMвоMIMA (DASYLLIS) GROSSA (Fabr.) 1

On page 63 , Dr. Plath states that he has never seen the near relative of $B$. grossa, $B$. thoracica (Fabr.), attack bumblebees, although he believes it probable that this species may do so. Thoracica is in general much more common in Southern New England than grossa, but I have never seen it feeding on bumblebees either, although I have on several occasions seen thoracica strike bumblebees in flight and unsuccessfully grapple them, indicating that the spirit at least is willing.

${ }^{1}$ The bumblebees herein referred to as prey of Asilids in New England were all workers and males of the following species listed in order of frequency: Bombus vagans F. Sm., B. impatiens Cress., B. perplexus Cress., B. affinis Cress., B. fervidus (Fab.), B. terricola Kby., and $B$. bimaculatus Cress. Some of these were recorded in my papers on Asilid Prey, Psyche XXI, No. 6, pp. 192-198 (1914) and Psyche XXX, No. 2, pp. 41-45 (1923). 

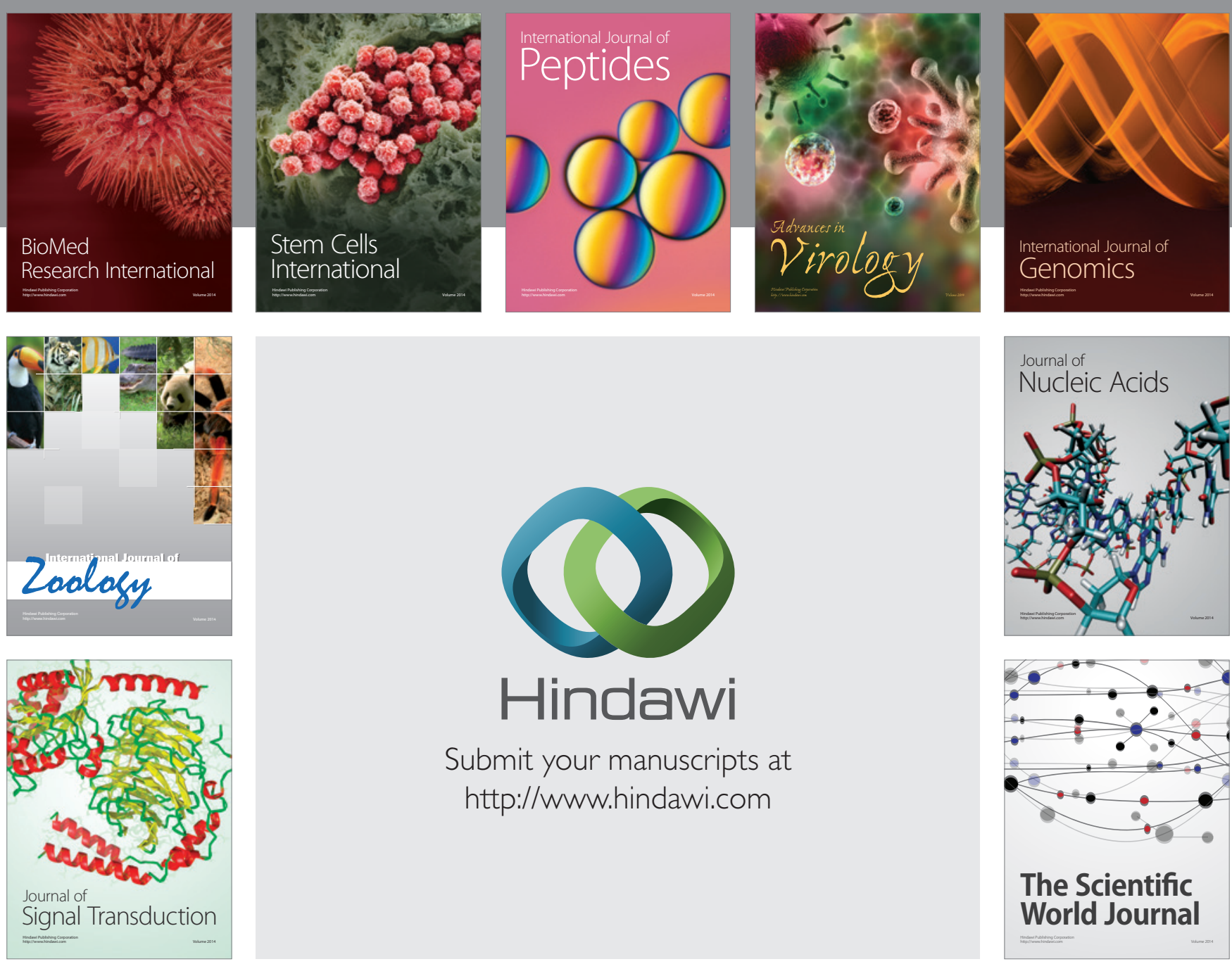

Submit your manuscripts at

http://www.hindawi.com
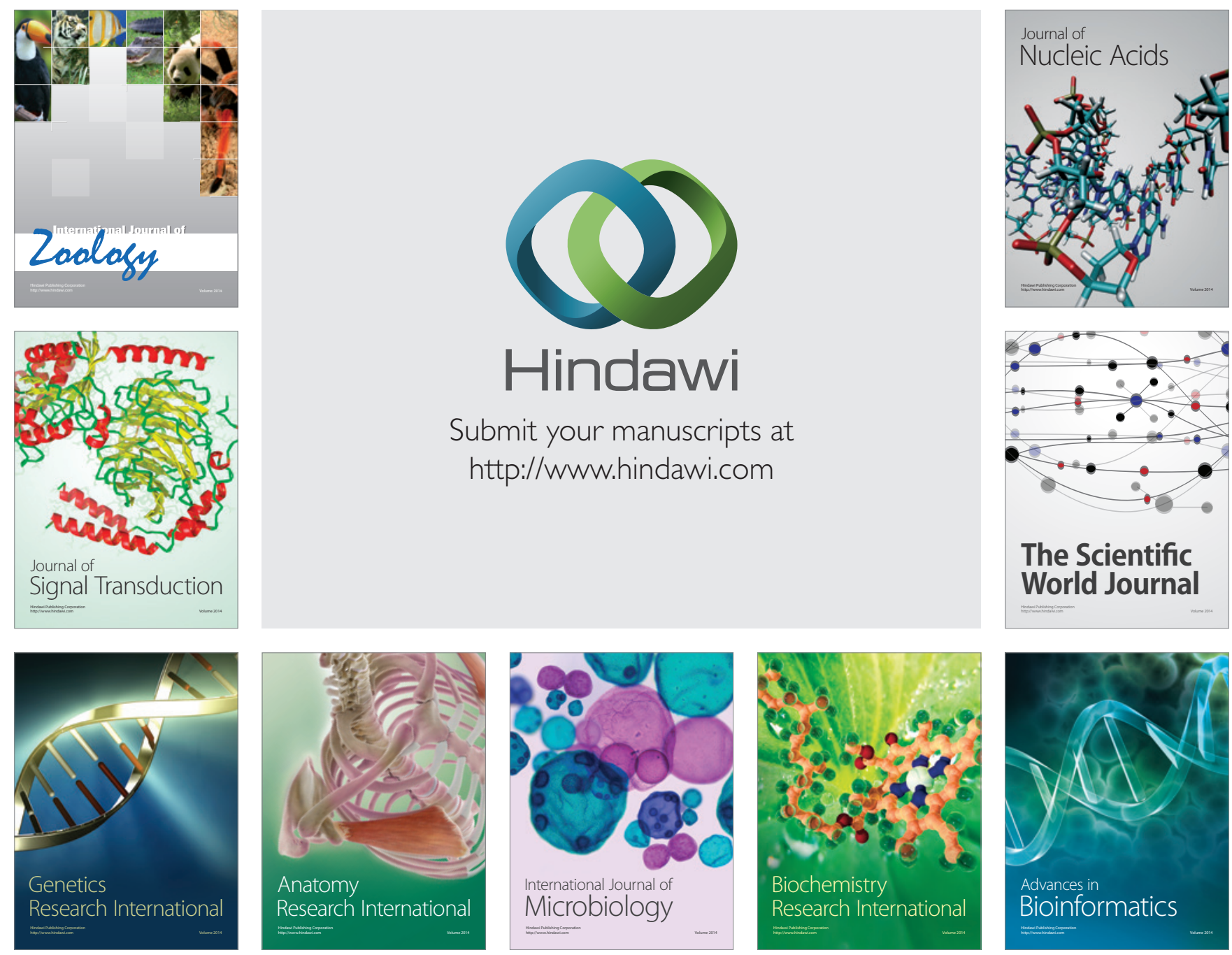

The Scientific World Journal
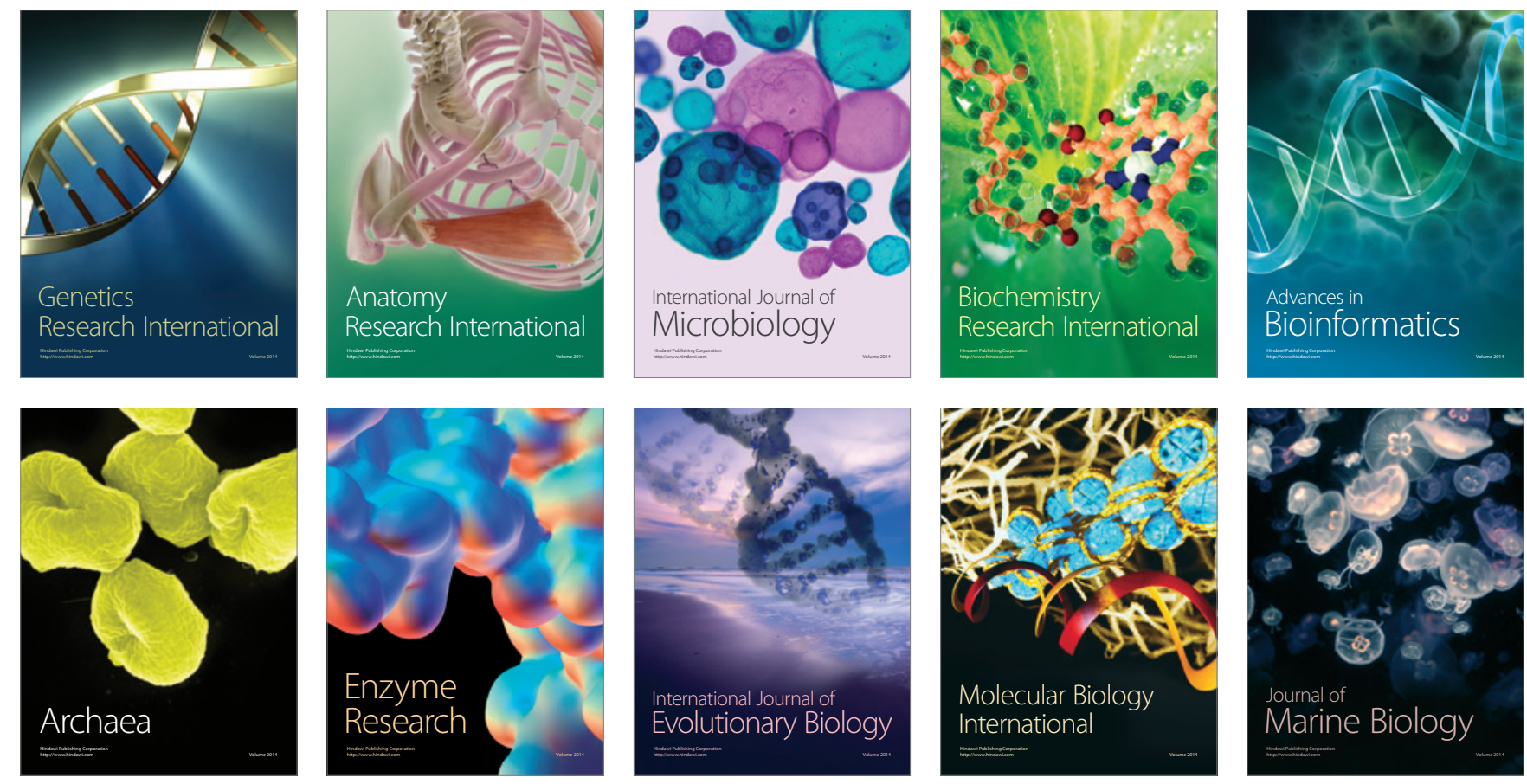